\title{
Fuzzy Expert System Applied in Hiring Ratings and Long Term Job Performance Prediction
}

\author{
Dana Balas-Timar, Valentina E. Balas, Alina Costin \\ Aurel Vlaicu University of Arad, Arad, Romania \\ Email: dana@xhouse.ro
}

Received 26 June 2014; revised 29 July 2014; accepted 16 August 2014

Copyright (C) 2014 by authors and Scientific Research Publishing Inc.

This work is licensed under the Creative Commons Attribution International License (CC BY). http://creativecommons.org/licenses/by/4.0/ cC) (7) Open Access

\begin{abstract}
This paper is presenting a model for a better prediction of long term job performance as seen by a Multinational Company from the West side of Romania (51 staff). This study is discussing a human resources procedure on recruiting assessment and its valid connection to the annual personnel evaluation individual scores, by analyzing archival data. Results conclude that age, gender, professional expertise, year of hiring, numeric and verbal abilities and interview score can predict job performance. Our hypothesis states that if we replace the classical weighted scoring algorithm with a fuzzy expert system, we will provide a better prediction of long term job performance.
\end{abstract}

Keywords

Cognitive Abilities, Hiring Rating, Fuzzy Expert System, Job Performance

\section{Personal Psychological Factors That Predict Job Performance}

There are two trends that have influenced research in factor predicting job performance. One is represented by Hunter's research focused on cognitive ability and the other one is represented by Goleman (1998) [1], Sonnentag and Lange (2002) [2], Nash (2003) [3] and Fiore (2011) [4] aiming interpersonal or soft skills.

Cognitive ability is considered to be the primary determinant of job performance (Schmidt et al. 1986) [5]-[9] and the relationship between ability and performance is stabile over time (Hunter, 1986 [10]; Schmidt \& Hunter, 1996 [11]; Schmidt, Hunter, Outerbridge \& Goff, 1988 [12]). There has also been found strong evidence that cognitive ability maintains its influence after the initial stages of employment, when employees are trained on how to perform on specific tasks and remains the major trigger of performance among senior employees (Schmidt \& Hunter, 1986 [13]). 
The ability to interact with others may be a big differentiator in how successful people are in personal or professional life. Frequently referred to as interpersonal or soft skills, the ability to communicate effectively, to respond to other's needs and to assist or support others to achieve their goals, to put foreward pesonal needs, handle diplomatically and assertivelly conflicts, are considered to be critical behavioral competencies. Labour market dinamics has yelled that in most jobs it is essential for candidates to own professional knowledge, technical expertise and skill, but without interpersonal skills one will certainly struggle to create and maintain healty relationships. Ultimately these efforts can negatively impact employees career paths and also their ability to act as part of a team.

There is also evidence that interpersonal skills, referred as social or people skills, social competencies, soft skills, social self-efficacy, and social intelligence represent important factor for success in schooling and work (Salas, Bedwell, and Fiore, 2011 [14]; Ferris, Witt, and Hochwarter, 2001 [14]; Hochwarter et al., 2001 [15]; Klein et al., 2006 [16]; Riggio, 1991 [17]; Schneider, Ackerman, and Kanfer, 1996 [18]; Sherer et al., 1982 [19]).

Hunter (1986) [10] reviewed the validities of a range of different selection predictors. The authors examined the ability of such predictors as cognitive tests, job tryouts, interviews, biographical data forms, interest tests, age, and education in predicting job performance in a wide variety of occupations. The main criterion of job performance used in this research was ratings of performance made by supervisors.

Overall, for entry-level jobs, Hunter and Hunter found that ability tests were the most accurate single predictors. Ability tests are a combination of cognitive tests (tests of verbal and numerical reasoning) and psychomotor tests. They claimed that “... ability tests are valid across all jobs in predicting job proficiency” (Hunter, $1986[10])$.

In a review of the literature, Schmidt and Hunter (2004) [7] found that the correlation between general mental ability and performance on the job ranged from 0.31 to 0.73 . They also found that validity coefficients between cognitive ability and job performance were strongest for jobs high in complexity. Validity generalization allows justification for the use of a test in a new setting if there is accumulated validity evidence for the same or similar type of job (Gatewood \& Field, 2001) [7]. Cognitive ability testing has been shown to have validity generalization in predicting performance (Schmidt \& Hunter, 1986 [9]; Viswesvaran \& Ones, 2002 [20]). The strongest validity for ability tests has been found for jobs that are complex and require high levels of information processing (Gatewood \& Field, 2001 [7]). Thus, selection testing and its relevance to later job performance in a complex technology organization with cognitively demanding jobs, are appropriate to address the effectiveness of an aptitude test.

One of the most common forms of assessment, cognitive ability testing, addresses general knowledge and capabilities. These tests are often characterized as measures of aptitude used to determine a person's ability to learn (Hunter, 1986 [10]; Hunter\& Schmidt, 1996 [11]; Schmidt, 2002 [19]). Cognitive ability tests often include measures of verbal, mathematical, memory, and reasoning abilities (Gatewood \& Field, 2001 [7]). Reasoning skills are commonly measured (Gatewood \& Field, 2001 [7]), but data manipulation is less commonly assessed. In comparison to other types of assessments, validity coefficients for cognitive ability tests show they are the most effective predictor of job performance across all job types (Hough \& Oswald, 2000 [9]; Schmidt \& Hunter, 1996, 2004 [7]; Viswesvaran \& Ones, 2002 [20]). Ree, Earles, and Teachout (1994) [15] examined how both general cognitive ability and specific abilities predicted job performance criteria. Their results indicated that both general cognitive ability and specific abilities predicted performance criteria, however, specific abilities only added a small amount of predictive power above general cognitive ability. When the specific abilities were added to general cognitive ability the observed correlation increased to 0.60 .

Job or work analyses in organizations are conducted to highlight key skills and abilities that are necessary for successful job performance (Brannick \& Levine, 2002 [21]). These skills and abilities are often used to identify tests that may be used to screen job applicants. The use of tests should be guided by the knowledge, skills, abilities, and other characteristics that are identified as being critical to the job and job level. One type of test that is related to multiple job roles measures cognitive ability, because most jobs require a baseline of intelligence (Hough \& Oswald, 2000 [9]; Outtz, 2002 [14]; Ree, Earles, \& Teachout, 1994 [15]; Schmidt, 2002 [19]; Schmidt \& Hunter, 1998 [6]; Tenopyr, 2002 [22]). Despite wide acceptance of the efficacy of cognitive ability screening for applicants, there have been relatively few studies to determine the relationship between this screening and long term job performance outcomes. 
Focusing on cognitive abilities and long term job performance, S. Alexander (2007) [23] has studied archival data from over 3000 employees at an international technology company were used to assess how aptitude test scores relate to both objective and subjective job performance measures. Number of training courses did not have a significant relationship with test scores. Additionally, type of turnover did not moderate the relationship between aptitude test scores and job performance. These results indicate that although aptitude test score is related to long term job performance factors, other factors account for the majority of the variance. The implication is that aptitude should not be the sole consideration when predicting long term job success. This study addresses the relationship of one such screening test to outcomes across a period of up to 8 years.

\section{Overall Aspects of the Study Case}

First, confirm that you have the correct template for your paper size. This template has been tailored for output on the custom paper size $(21 \mathrm{~cm} \times 28.5 \mathrm{~cm})$.

The numerical and verbal ability test examined in this study is a standardized paper and pencil measure developed and validated in 2010, for use as part of the selection process of entry-level middle and top management applicants to engineering positions in a Multinational company situated in the West side of Romania. The test was designed to measure reasoning skills for individuals that were applying for positions requiring complex logical analyses, such as: quality engineer, manufacturing engineer, warehouse administrator, launch coordinator, master schedule, HR manager, plant controller, engineering manager, production manager, logistic manager, quality manager, controller, laboratory engineer, internal auditor, recruitment responsible, HR assistant, administration and payroll, material planner, traffic scheduler, customer quality engineer, packing responsible, incoming inspection engineer, process engineer, PPAP analyst, young graduate. All applicants had completed an engineering college and/or have between 1 and 13 years of work experience, professional background. Personal and motivational characteristics were assessed during the interview.

Numeric abilities test consists of 10 items, 5 measuring deductive reasoning and 5 measuring arithmetic problems. Verbal abilities test consist of 10 items, 5 measuring verbal similarity and 5 measuring syntax. Scales for both numeric and verbal abilities will assign rank 1, very week for 1 or two correct answers, rank 2, week for 3, 4 or 5 correct answers, rank 3, good, for 6, 7 or 8 correct answers and rank 4 very good, for 9 or 10 correct answers.

As for interview scores, the scale assigns 1 to 5 points, regarding levels of interpersonal communication, work motivation, fluency in English and orientation to objectives.

The annual evaluation rating regards the appreciated performance on a 1 to 5 scale (where 1 stands for-does not meet standards and 5 for-exceed standards) for the following aspects: job specific knowledge, quality/ quantity of work, communications, interpersonal skills, organization, planning and process thinking, judgment and decision making, customer satisfaction, teamwork, adaptability to change, management of human resources (not required for non-supervisory associates) and performance against objectives (optional-attach performance objectives).

A purpose of this study is to determine the usefulness of an aptitude test: verbal and numeric for predicting long-term job performance. The potential maximum length of employment for the participants in this study is 3 years. Thus, this study improves on previous validation efforts that have focused on short term job performance, collecting criterion measures only after several months on the job. Extending the length of time before collecting criterion data should provide an accurate reflection of employee performance.

The main purpose of this study is to observe if the formula that concludes on hiring rating represents a valid fact for the company or attention might be focused on other aspects or weighted in order to obtain a predictive score on job performance.

The company formula for calculating the hiring score consists of three weighted aspects:

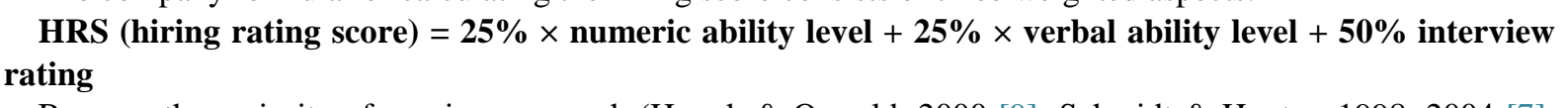

Because the majority of previous research (Hough \& Oswald, 2000 [9]; Schmidt \& Hunter, 1998, 2004 [7]; Viswesvaran \& Ones, 2002 [23]) has found a positive relation between scores on cognitive abilities tests and job performance, this outcome is expected to be consistent for a long term measure of job performance. Due to interrelations among job performance, promotions and salary (Gatewood \& Field, 2001) [7], aptitude testing re- 
sults should also be positively related to promotions and raises. A review of longitudinal studies of aptitude test scores by Schmidt and Hunter (2004) [24] found that aptitude predicted both movement in job hierarchy and income. These considerations lead to:

Hypothesis 1: Hiring rating score (composed by numeric and verbal abilities scores and interview rating score) will be positively related to supervisory ratings of job performance (1 to 3 years from hiring year) and salary.

Hypothesis 2: Hiring rating score (HRS) calculated with Fuzzy Expert System will have an increased impact on predicting long-term job performance (1 to 3 years from hiring year) than classical weighted calculated HRS.

\section{Fuzzy Expert System Applied in Hiring Ratings}

Fuzzy logic represents a mathematical technique for dealing with imprecise data and problems that have many solutions rather than one. Although it is implemented in digital computers, which ultimately make only yes-no decisions, fuzzy logic works with ranges of values, solving problems in a way that more resembles human logic. Fuzzy logic is used for solving problems with expert systems and real-time systems that must react to an imperfect environment of highly variable, volatile or unpredictable conditions. Fuzzy logic circumvents abrupt changes in operation that could result from relying on traditional either-or and all-or-nothing logic (Zadeh, 1965) [25].

To facilitate HR decision during talent management process, we have developed a decision making model to assist de department in taking the hiring or not hiring decision, based on the future predicted job performance of current employees. The decisional model proposed in this paper is based on a Sugeno fuzzy inference system designed in Fuzzy Toolbox-MATLAB.

The starting point in the development of this expert system will be setting input variables. These input variables (input). The candidate's personal information is collected by recruitment specialists through CV screening, interview, numerical and verbal abilities tests. Output variables (output) will consist of ranking scores between 1 and 5, (Figure 1) each assigned carefully and having as ultimate outcome a formula that will predict long term job performance. As described above, company's formula for calculating hiring ratings consists in cumulated weighted of numeric and verbal abilities scores and interview rating. As we will further see, this composite score represents a good predictor for long term job performance.

Thus, as input, our expert system will record the scores received by candidates: numeric ability score, verbal ability score, interview rating and candidate's age and years of background experience. The five independent variables entered as input to the expert system will serve to shape the output, the real occupational profile of the candidate in order to take the hiring decision. This process will take into account the best candidates for compa-

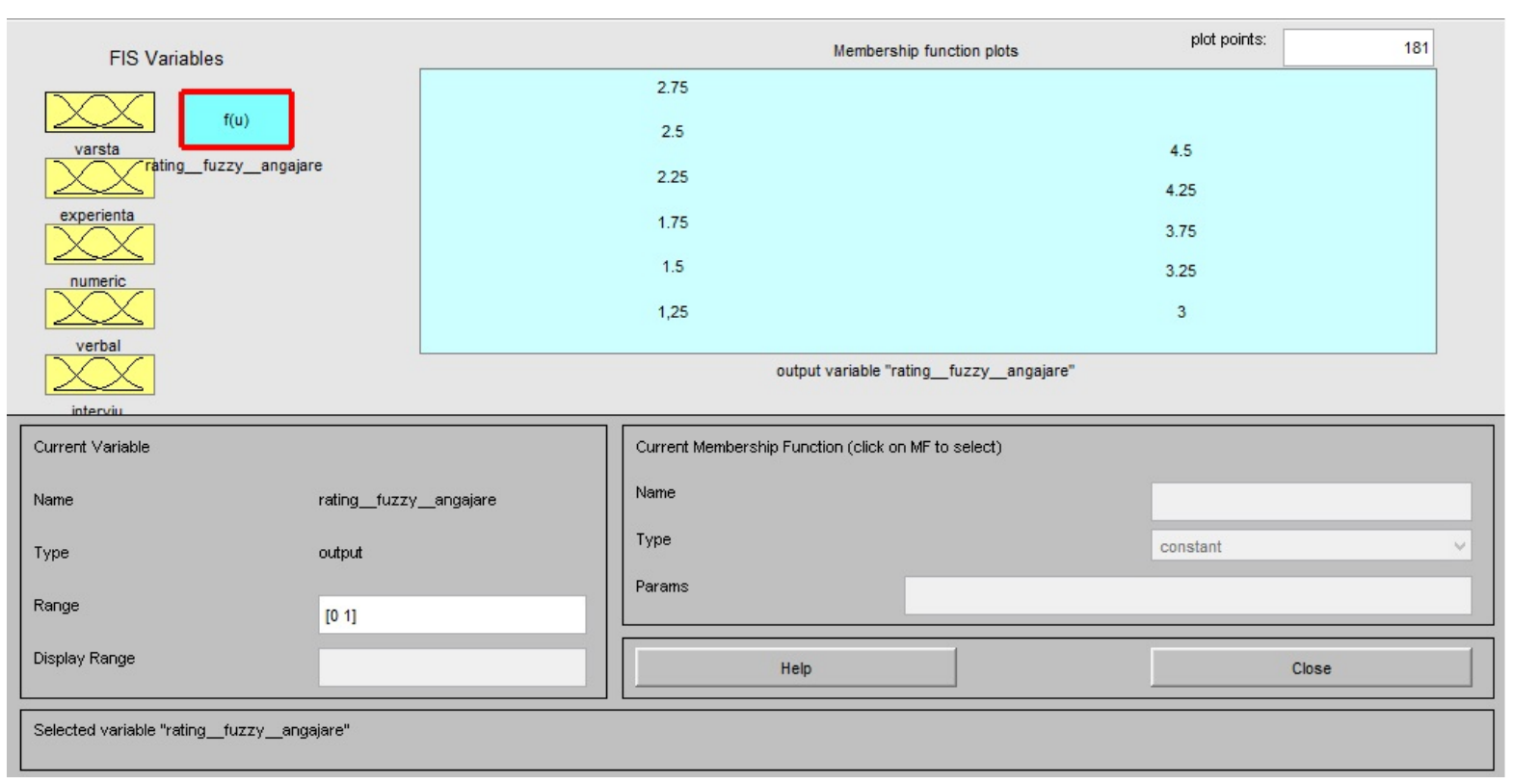

Figure 1. Fuzzy expert system input and output data. 
ny's vacancies; candidates that will long term demonstrate high levels of performance (from 1 to 3 years from hiring year).

Facing this dilemma, weather to hire a short term or long term performance candidate, companies have chosen a professional profile based on their size and their turnover ratio. In human resources context, turnover or staff turnover is the rate at which an employer loses employees in a certain period of time, usually expressed in a percentage. Simple ways to describe it are "how long employees tend to stay". If an employer is said to have a high turnover relative to its competitors, it means that employees of that company have a shorter average tenure than those of other companies in the same industry. High turnover may be harmful to a company's productivity if skilled workers are often leaving and the worker population contains a high percentage of novice workers. Companies also often track turnover internally across departments and divisions or other demographic groups such as turnover of women versus turnover of men.

The reason for choosing ranking scores ( 1 for low long term performance and 5 for high long term performance) as outputs is the need of a relevant hierarchy between candidates, as well as for computing Hierarchical Multiple Regression analysis.

The fundamental operation of this expert system is to setup multiple decision rules that will automatically assign a rank from 1 to 5 to each candidate, depending on the age, years of background experience, interview rating and numerical and verbal abilities levels. The output from the expert system will estimate the level of future long term job performance, in order to make an optimal decision weather hiring or not hiring the candidate.

Fuzzification comprises the process of transforming crisp values into grades of membership for linguistic term of fuzzy sets. The membership function is used to associate a grade to each linguistic term. Fuzzification is the process of changing a real scalar value into a fuzzy value. This is achieved with the different types of fuzzifiers. There are generally three types of fuzzifiers which are used for the fuzzification process; they are singleton, Gaussian and trapezoidal and triangular fuzzifiers (Zadeh, 1965) [25].

Specifically, we used as input five variables, three of them (numeric abilities, verbal abilities and interview rating) having as qualitative descriptors: low and high, and two of them (age and years of background experience) having qualitative descriptors: low, medium and high. These descriptors are defined according to the score obtained by the candidates on each numeric abilities, verbal abilities and interview rating; scores between 1 and 2.50 will become "low" and scores between 2.5 and 5 will become "high". As for age, 25 to 28 years will become "low", 29 to 34 will become "medium" and 35 to 39 will become "high". In the same manner, the background experience will be fuzzified as follows: 1 to 3 years will become "low", 4 to 8 years will become "medium" and 9 to 13 years will become "high".

For modeling the system inputs and outputs there were used trapezoidal and triangular type sets. The outputs of the expert system refer to 11 ranks, from 1.25 to 4.50 , correspondent to the estimated level of future job performance. Expert system's core is represented by the inference rules, decision rules that establish correspondences between variables, in order to determine the level of professional expertise in order to predict a long term job performance.

Figure 2 summarizes the inference rules proposed by this model. Rules proposed by this model emerged from patterns of job performance among collected data (numeric and verbal abilities, interview ratings and performance ratings). Total rules would be 72 , but most of them are redundant, so we have designed 30 rules, addressing each level of professional expertise (driven from scores to numeric and verbal abilities and interview ratings), from the lowest to the highest level. Given the fact that we have found positive strong correlations between hiring rating scores and job performance ratings of $0.958, p<0.001$, we have considered that simulating data (hiring rating scores) with fuzzy inference rules we would obtain a even better correlation between these two variables. Our objective in proposing this fuzzy algorithm for calculating hiring rating scores will provide a better understanding of future performance of current candidates that continuously apply for new job vacancies. In support for this, we have found positive strong correlations between Fuzzy hiring rating scores and job performance ratings of $0.970, p<0.001$, thus this algorithm calibrated to actual statistical data, will provide a much easier way to decide whether to hire or not individuals. Usually HR decisions especially taken by less experienced evaluators tend to be subjective, without an expert system assisting them throughout the selection process. This is a common situation when companies externalize the recruiting and selection process to private employment consultancy agencies that cannot understand completely company's culture and values and best candidate profiles. Agencies tend to recommend many candidates with different profiles matching specific job descriptors given by the company, to be sure that they succeed in finding the appropriate individuals. 


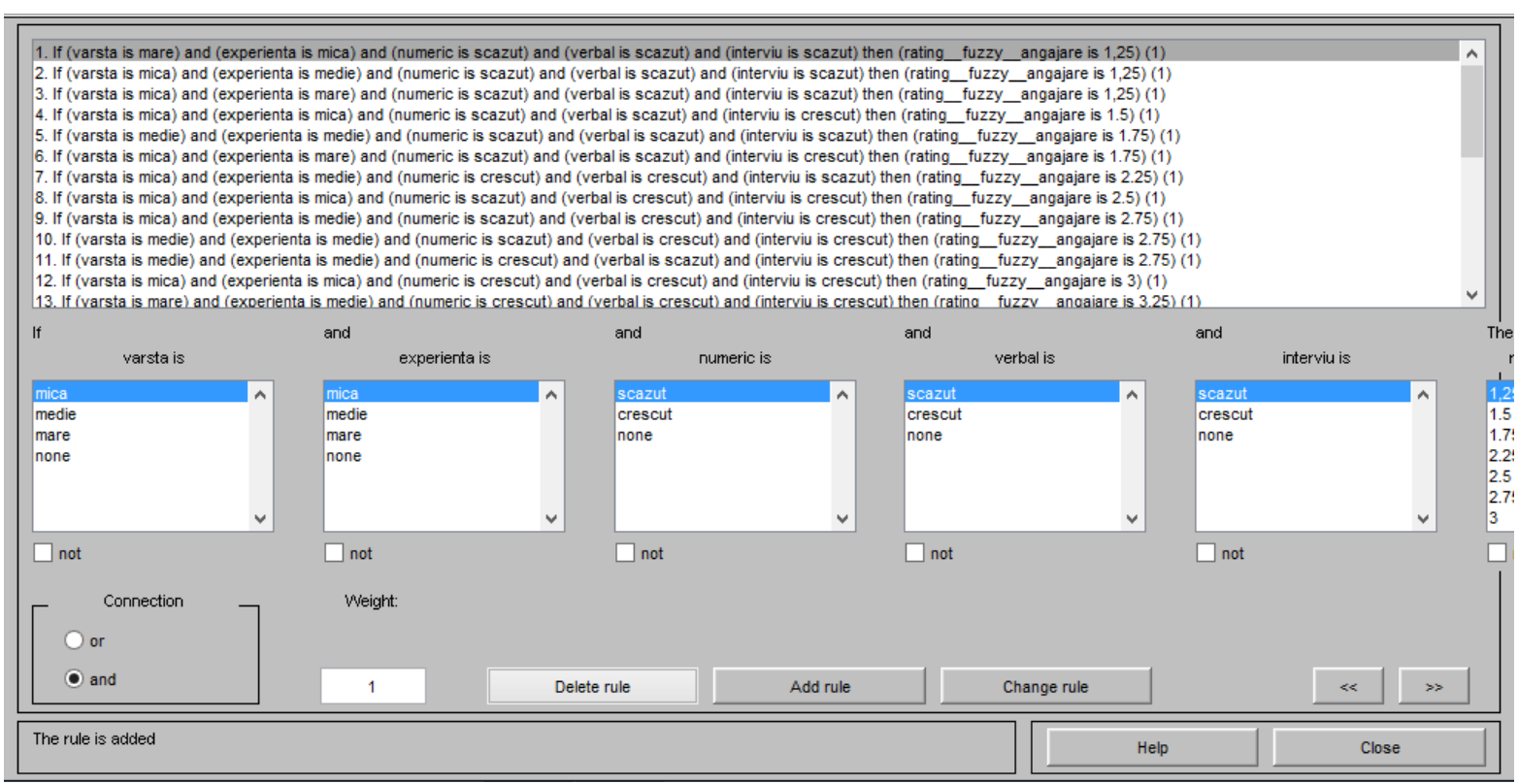

Figure 2. Decisional rules for calculating the estimated future job performance.

Most hiring decision problems will appear in the situation that for a certain vacancy, agency will recommend a short list of 5 candidates. Company has to take the final decision, by assessing again short list candidates. This process is frustrating for both companies that have already externalized this selection process and as well for candidates, which have already been interviewed and tested. By proposing this Fuzzy scoring algorithm that correlates strongly $(0.970, p<0.001)$ with job performance ratings done after 1 to 3 years from hiring, we offer background arguments for taking best decisions in hiring new employees.

In order to a better prediction of future job performance, we have taken into account not only scores obtained from numerical and verbal abilities test and interview rating but also candidate's age and years of background experience which companies with a low ratio of turnover, consider relevant personal aspects.

For example, if candidates are aged between 25 to 28, with background experience less than 3 years, scoring low on numeric and verbal abilities and interview, they will be assigned with a Fuzzy score of 1.25, which represents the lowest value of the scale. Such candidates will be rejected, as considered to not demonstrate future job performance in this particular context. On the other hand, candidates with ages between 35 and 39, with background experience more than 9 years, scoring high on numeric and verbal abilities and interview, they will be assigned to a Fuzzy score of 4.50, which represents the highest value of the scale, for this particular situation. These inference rules, in fact candidates profiles, were driven from actual database.

After determining the inference rules for assigning to each candidate one of 11 specific categories of future job performance (from 1.25 to 4.50 scores), we present some areas obtained from the simulation process.

If we take into account the numeric abilities and years of background experience as axes, (Figure 3 ) the other variables are silent in the picture; one can find that priority will be given to candidates with high level of numeric abilities and medium background experience. Also candidates with low numeric abilities and both low and high background experience will be given a chance on entry level positions. Candidates with low numeric abilities and medium (4 to 8 years) background experience will not be hired in this particular context. This last position is considered not to bring relevant future job performance.

If we look at the numeric abilities and age as axes (Figure 4), the other variables are silent in the picture; one can find that priority will be given to candidates with both high level of numeric abilities and ages between 25 and 28. Also candidates with low numeric abilities and ages between 35 and 39 will be given a chance on entry level positions. Candidates with low numeric abilities and ages between 25 and 34 will not be hired in this particular context. This last position is considered not to bring relevant future job performance.

Looking at the interview rating and age as axes (Figure 5), the other variables are silent in the picture; one can find that priority will be given to candidates with both high interview ratings and ages between 25 and 28 . Also candidates with low interview ratings and ages between 35 and 39 will be given a chance on entry level 


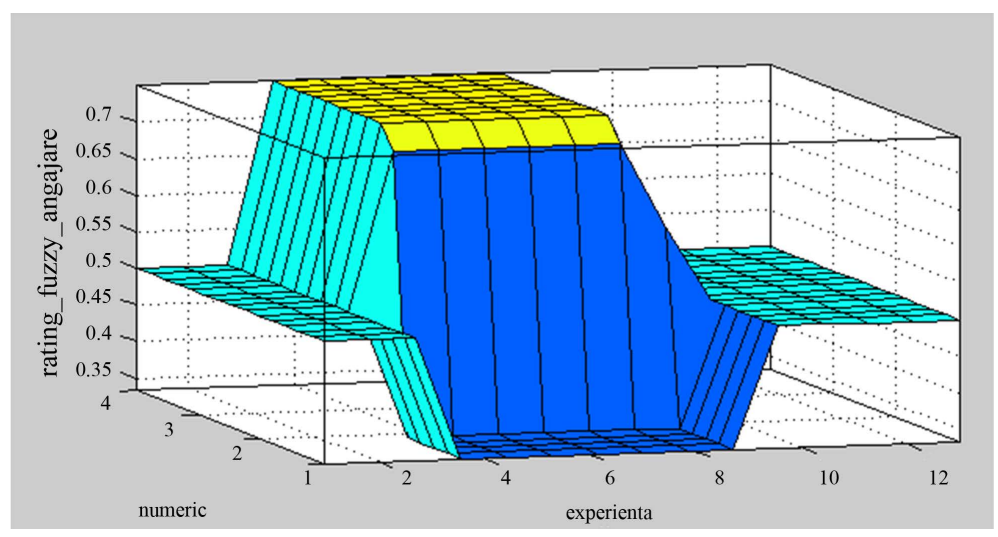

Figure 3. Numeric abilities (numeric) and background experience (experienta) surface.

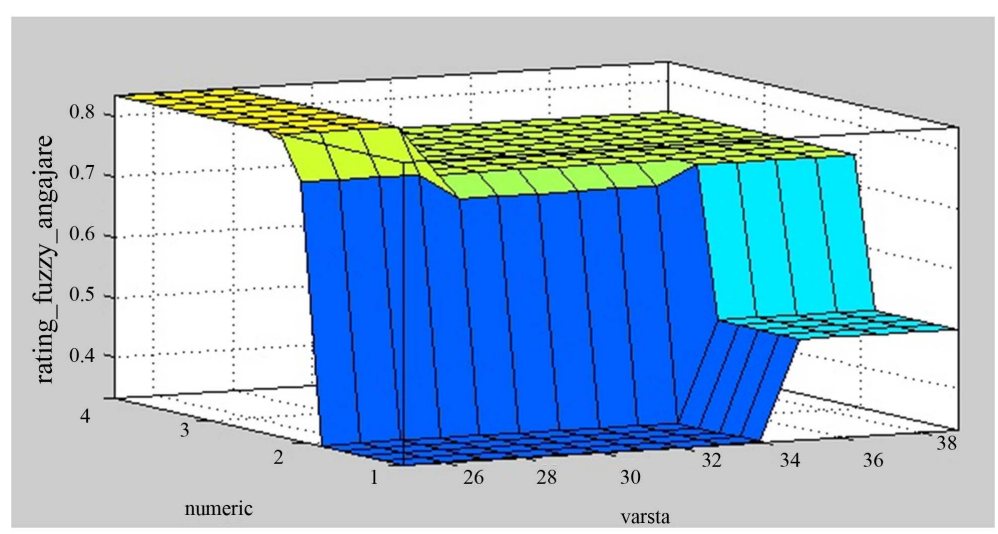

Figure 4. Numeric abilities (numeric) and age (varsta) surface.

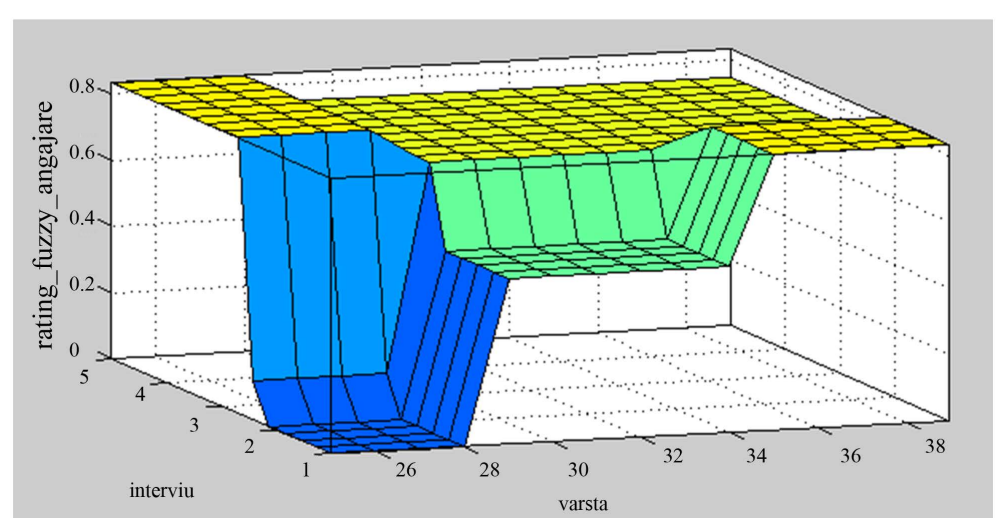

Figure 5. Interview rating (interviu) and age (varsta) surface.

positions. The majority of candidates with high interview ratings and ages between 28 and 39 will have good chances to be hired in our company. Candidates with low interview ratings and ages between 25 and 28 will not be hired in this particular context. This last position is considered not to bring relevant future job performance.

If we focus on the interview rating and background experience as axes (Figure 6), the other variables are silent in the picture; one can find that priority will be given to candidates with both medium background experience (4 to 8 years) and high interview ratings. Candidates with low interview ratings and background experience between 1 and 3 years and as well as 9 to 13 years will not be hired in this particular context. This last position is considered not to bring relevant future job performance. 
If we look at the interview rating and numeric abilities as axes (Figure 7), the other variables are silent in the picture; one can find that priority will be given to candidates with both high interview ratings and high level of numeric abilities. Also candidates with low interview ratings and low numeric abilities will be given a chance on entry level positions. Candidates with low numeric abilities and high interview scores will not be hired in this particular context. This last position is considered not to bring relevant future job performance.

Looking at the age and background experience as axes (Figure 8), the other variables are silent in the picture; one can find that priority will be given to candidates with ages between 25 and 28 and medium background experience (4 to 8 years). Also candidates with ages between 29 and 39 and medium background experience (4 to 8 years) will be given a chance on entry level positions. Candidates of all ages with background experience between 1 and 3 years and 9 and 13 years will not be hired in this particular context. This last position is considered not to bring relevant future job performance.

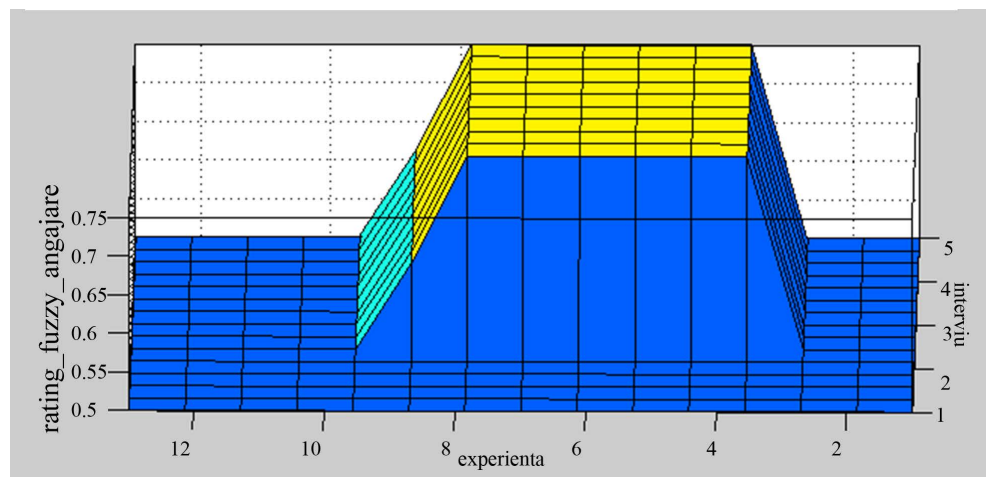

Figure 6. Interview rating (interviu) and background experience (experienta) surface.

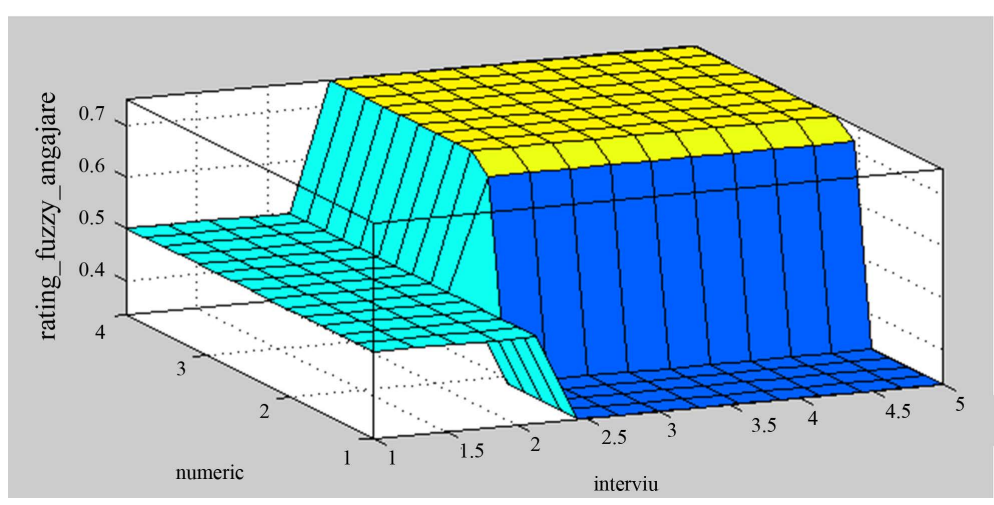

Figure 7. Interview rating (interviu) and numeric abilities (numeric) surface.

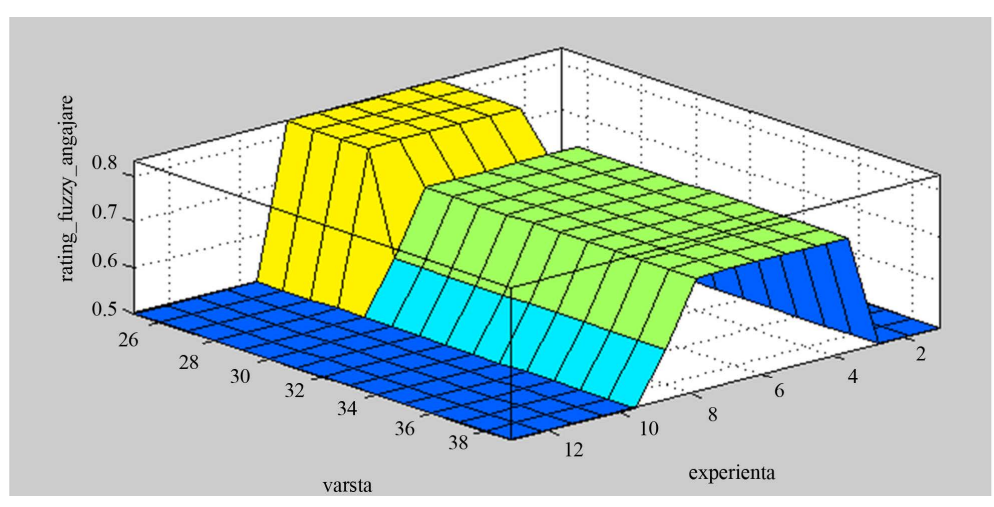

Figure 8. Age (varsta) and background experience (experienta) surface. 
If we look at the verbal abilities and background experience as axes (Figure 9), the other variables are silent in the picture; one can find that priority will be given to candidates with high level of verbal abilities and medium background experience (4 to 8 years). Also candidates with low level of verbal abilities and both background experience of 1 to 3 years and 9 to 13 years will be given a chance on entry level positions. Candidates with low verbal abilities and medium to high (4 to 13 years) background experience will not be hired in this particular context. This last position is considered not to bring relevant future job performance.

Focusing on verbal abilities and age as axes (Figure 10), the other variables are silent in the picture; one can find that priority will be given to candidates with both high level of verbal abilities and ages between 25 and 28 . Also candidates with low verbal abilities and ages between 25 and 28 and as well as 35 and 39 will be given a chance on entry level positions. Candidates with low verbal abilities and ages between 29 and 34 will not be hired in this particular context. This last position is considered not to bring relevant future job performance.

If we look at the verbal abilities and numeric abilities as axes (Figure 11), the other variables are silent in the picture; one can find that priority will be given to candidates with both high level of verbal abilities and numeric abilities. Also candidates with low verbal abilities and low verbal abilities will be given a chance on entry level positions. Candidates with low verbal abilities and high level of numeric abilities and vice versa will not be hired in this particular context. This last position is considered not to bring relevant future job performance.

This last results perfectly disposes the "false negative" candidates, that were hired by our company, being the best candidates that have applied at that time.

The whole picture of future job performance thus is based on a intercorrelation between factors such as age, background experience, numeric and verbal abilities and interview ratings, where each variable bring substantial value to each possible aspect encountered in recruitment practice.

This type of expert system assisted recruitment procedure is designed to focus the attention on the relevant aspects of all input variables, in order to make the optimal recruiting decision for a future job performance of the candidate. Recruiting staff tend to consider that there should be given a more important position to cognitive abilities, or interview rating or personal background information in order to hire the best candidate. As we have

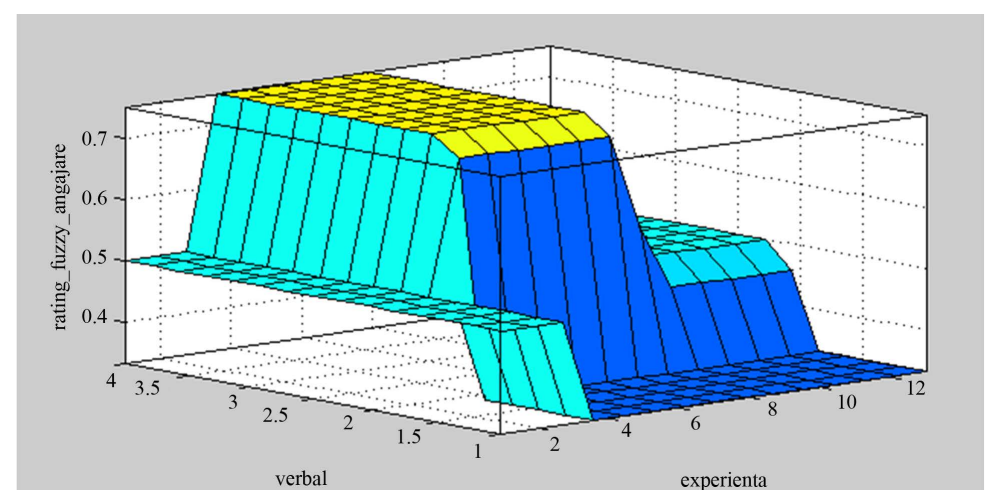

Figure 9. Verbal abilities (verbal) and background experience (experienta) surface.

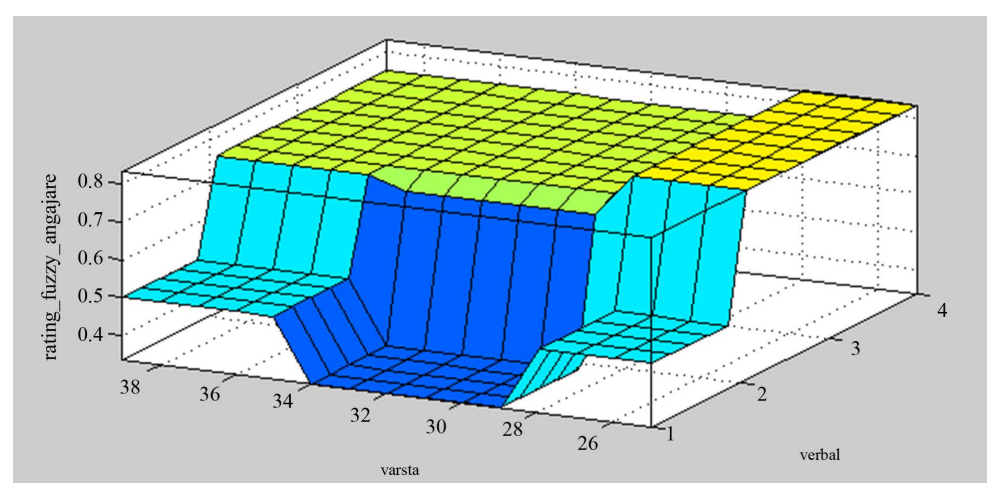

Figure 10. Verbal abilities (verbal) and age (varsta) surface. 


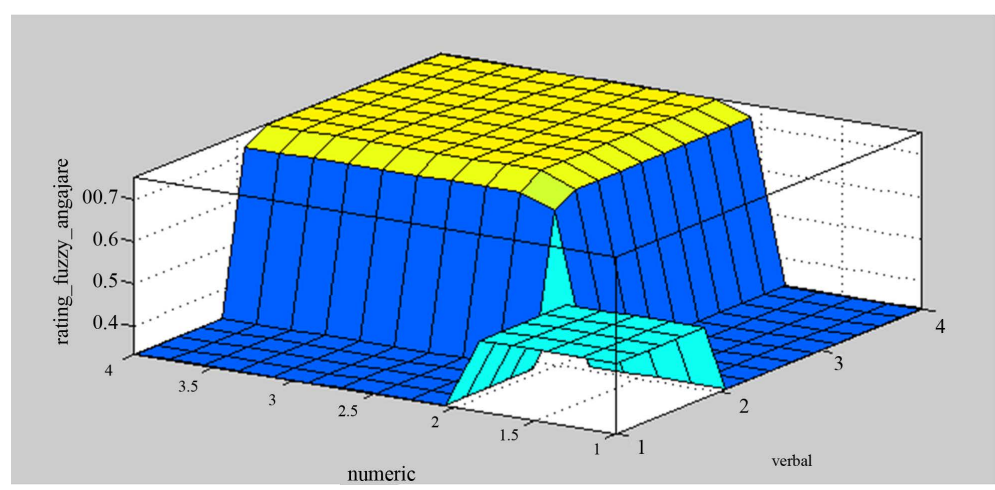

Figure 11. Verbal abilities (verbal) and numeric abilities (numeric) surface.

seen, all aspects are important if we try to look further, to future job performance. Sometimes it is absurd to reject a candidate that has high level of cognitive abilities, or to hire one with low level of cognitive abilities, but if we think at the context of industrial work, most of the time requiring routine activities and following the procedures, we may see things differently, like fuzzy logic does.

\section{Findings}

First, confirm that you have the correct template for your paper size. This template has been tailored for output on the custom paper size $(21 \mathrm{~cm} \times 28.5 \mathrm{~cm})$.

Archival data from 51 current employees who completed an aptitude test as part of the employment selection process are included in this study. Data were gathered for job applicants who took the aptitude test and were hired between 18.05.2010 and 16.09.2013. These archival data were collected in March 2014. The aptitude test was administered during the application process, after an initial screening but prior to a formal interview with a hiring manager, since the opening of the company in Arad, in 2010. The archival data include demographic information and organizational data. Of the participants $56.9 \%$ are male. Regarding the hiring year $5.9 \%$ became employees in 2010, 19.6\% became employees in 2011, 33\% became employees in 2012 and $41.2 \%$ became employees in 2013.

Employees are aged between 25 and 39. The range of incomes varies from 1.800 Ron (Young graduate) to 37.957 Ron (Production Manager).

Table 1 provides the frequency, minimum, maximum, means and standard deviations for the criteria measures.

Before testing our hypothesis, we consider observing the reliability of cognitive ability test used by the company. As emphasized, cognitive abilities will refer to: deductive reasoning and arithmetic problems for numeric abilities and verbal similarity and syntax for verbal abilities.

As seen in Table 2, we have obtained a relevant Cronbach's Alpha coefficient of 0.752, fact that demonstrates the reliability of the cognitive assessment test. If we take a closer look, we will find that even if 1 of the 4 subscales is deleted, none of them succeeds in increasing the reliability coefficient. Although we have strong proof that our cognitive assessment test is reliable on studied population, we have no evidence of validity and reliability on other population.

Testing if gender supposes significant differences in cognitive tests results, a coefficient of $\mathrm{F}=1.546, p<$ 0.001 , deductive reasoning mean for males $\mathrm{m}=3.55$ and females $\mathrm{m}=2.45$ demonstrates that male candidates score better than females. A coefficient of $\mathrm{F}=0.105, p<0.001$, arithmetical problems mean for males $\mathrm{m}=3.66$ and females $\mathrm{m}=2.45$ demonstrates that male candidates score better than females (Table 3 ).

Before testing the hypotheses, correlations were calculated to determine the strength of relationships between the cognitive ability test score, interview rating, both classical and Fuzzy calculated hiring scores and performance ratings. As seen in Table 4, the majority of the individual performance criteria (6), (7), (8), (9), (10), (11) are significantly related to numeric (4) and verbal test score (5).

As seen in Table 4, both age and years of background experience positively correlates to all other variables of the study. This should drown attention to the fact that both candidate's age and background experience should be treated with a lot more importance when calculating hiring score. This finding guided us in reviewing the al- 
Table 1. Descriptive statistics for: age, years of background experience, old and new income.

\begin{tabular}{cccccc}
\hline & N & Minimum & Maximum & Mean & Std. Deviation \\
\hline Age & 51 & 25 & 39 & 31.51 & 4.120 \\
Years of background experience & 51 & 1 & 13 & 4.88 & 2.651 \\
Old income & 51 & 1800 & 37,957 & 6650.75 & 6202.921 \\
New income & 51 & 1800 & 37,957 & 6966.65 & 6348.590 \\
Valid N (listwise) & 51 & & & & \\
\hline
\end{tabular}

Table 2. Reliability of cognitive test using Cronbach’s Alpha.

\begin{tabular}{cc}
\hline & Reliability Statistics \\
\hline Cronbach's Alpha & Cronbach’s Alpha Based on Standardized Items \\
\hline 0.752 & 0.752 \\
\hline
\end{tabular}

\begin{tabular}{|c|c|c|c|c|c|c|c|c|}
\hline \multicolumn{9}{|c|}{ Item-Total Statistics } \\
\hline Scales & M & SD & $\mathrm{N}$ & $\begin{array}{l}\text { Scale Mean if } \\
\text { Item Deleted }\end{array}$ & $\begin{array}{l}\text { Scale Variance } \\
\text { if Item Deleted }\end{array}$ & $\begin{array}{c}\text { Corrected } \\
\text { Item-Total } \\
\text { Correlation }\end{array}$ & $\begin{array}{l}\text { Squared Multiple } \\
\text { Correlation }\end{array}$ & $\begin{array}{l}\text { Cronbach's Alpha if } \\
\text { Item Deleted }\end{array}$ \\
\hline $\begin{array}{l}\text { Deductive } \\
\text { reasoning }\end{array}$ & 3.08 & 1.181 & 51 & 9.47 & 5.974 & 0.583 & 0.485 & 0.676 \\
\hline $\begin{array}{l}\text { Arithmetic } \\
\text { problems }\end{array}$ & 3.14 & 1.114 & 51 & 9.41 & 6.167 & 0.601 & 0.483 & 0.664 \\
\hline Verbal similarity & 3.14 & 1.000 & 51 & 9.41 & 7.167 & 0.479 & 0.341 & 0.731 \\
\hline Syntax & 3.20 & 1.020 & 51 & 9.35 & 6.833 & 0.536 & 0.372 & 0.702 \\
\hline
\end{tabular}

Table 3. Gender in numeric and verbal abilities test scores.

\begin{tabular}{|c|c|c|c|c|c|c|c|c|c|}
\hline & Gender & $\mathrm{N}$ & M & $\mathrm{SD}$ & $\mathrm{F}$ & Sig. & $\mathrm{t}$ & df & Sig. (2-tailed) \\
\hline \multirow{2}{*}{ Deductive reasonin } & M & 29 & 3.55 & 0.948 & 1.546 & 0.220 & 3.675 & 49 & 0.001 \\
\hline & $\mathrm{F}$ & 22 & 2.45 & 1.184 & & & 3.564 & 39.401 & 0.001 \\
\hline \multirow{2}{*}{$\begin{array}{c}\text { Arithmetical } \\
\text { problems }\end{array}$} & M & 29 & 3.66 & 0.936 & 0.105 & 0.747 & 4.481 & 49 & 0.000 \\
\hline & $\mathrm{F}$ & 22 & 2.45 & 0.963 & & & 4.464 & 44.700 & 0.000 \\
\hline \multirow{3}{*}{ Vebal similarir } & M & 29 & 3.10 & 1.047 & 0.011 & 0.916 & -0.275 & 49 & 0.785 \\
\hline & & & & & & & & & \\
\hline & $\mathrm{F}$ & 22 & 3.18 & 0.958 & & & -0.278 & 47.220 & 0.782 \\
\hline \multirow{3}{*}{ Sintax } & M & 29 & 3.03 & 1.052 & 0.161 & 0.690 & -1.308 & 49 & 0.197 \\
\hline & & & & & & & & & \\
\hline & $\mathrm{F}$ & 22 & 3.41 & 0.959 & & & -1.325 & 47.278 & 0.192 \\
\hline
\end{tabular}

gorithm for calculating hiring score using Fuzzy Expert System, in order to gain a better long term prediction for overall job performance.

Hypothesis 1: Hiring rating score (composed by numeric and verbal abilities scores and interview rating score) will be positively related to supervisory ratings of job performance ( 1 to 3 years from hiring year) and salary. 
Table 4. Correlation matrix for analyzed variables $(\mathrm{N}=51)$.

\begin{tabular}{|c|c|c|c|c|c|c|c|c|c|c|c|c|}
\hline & M & SD & 1 & 2 & 3 & 4 & 5 & 6 & 7 & 8 & 9 & 10 \\
\hline Hiring year (1) & 2012.10 & 0.92 & - & & & & & & & & & \\
\hline Age (2) & 31.51 & 4.12 & -0.031 & - & & & & & & & & \\
\hline $\begin{array}{c}\text { Background experience. } \\
\text { years ( } 3 \text { ) }\end{array}$ & 4.88 & 2.65 & -0.193 & $0.780^{* *}$ & - & & & & & & & \\
\hline Numeric (4) & 2.73 & 0.87 & -0.105 & $0.390^{* *}$ & $0.495^{* *}$ & - & & & & & & \\
\hline Verbal (5) & 2.66 & 0.67 & 0.092 & $0.495^{* *}$ & $0.552^{* *}$ & $0.413^{* *}$ & - & & & & & \\
\hline Interview rating (6) & 2.80 & 0.81 & 0.003 & $0.352^{*}$ & $0.370^{* *}$ & $0.552^{* *}$ & $0.580^{* *}$ & - & & & & \\
\hline Hiring rating (7) & 2.75 & 0.68 & -0.009 & $0.465^{* *}$ & $0.524^{* *}$ & $0.763^{* *}$ & $0.738^{* *}$ & $0.933^{* *}$ & - & & & \\
\hline Fuzzy Hiring rating (8) & 2.83 & 0.75 & -0.035 & $0.522^{* *}$ & $0.582^{* *}$ & $0.734^{* *}$ & $0.725^{* *}$ & $0.904^{* *}$ & $0.970^{* *}$ & - & & \\
\hline Rating 2013 (9) & 3.09 & 0.69 & -0.050 & $0.532^{* *}$ & $0.598^{* *}$ & $0.688^{* *}$ & $0.719^{* *}$ & $0.911^{* *}$ & $0.958^{* *}$ & $0.983^{* *}$ & - & \\
\hline Old Salary (10) & 6650.75 & 6202.92 & $-0.329^{*}$ & $0.479^{* *}$ & $0.721^{* *}$ & $0.278^{*}$ & $0.423^{* *}$ & 0.216 & $0.328^{*}$ & $0.392^{* *}$ & $0.437^{* *}$ & - \\
\hline New Salary (11) & 6966.65 & 6348.59 & $-0.335^{*}$ & $0.483^{* *}$ & $0.728^{* *}$ & 0.275 & $0.416^{* *}$ & 0.196 & $0.313^{*}$ & $0.377^{* *}$ & $0.423^{* *}$ & $0.998^{* *}$ \\
\hline
\end{tabular}

"Correlation is significant at the 0.05 level (2-tailed); ${ }^{* *}$ Correlation is significant at the 0.01 level (2-tailed).

A regression analysis was conducted in order to measure the variability in job performance evaluation (Rating 2013) that can be accounted for hiring rating score (numeric and verbal abilities and interview rating).

Multiple regressions require a large number of observations, the number of participants must substantially exceed the number of predictor variables, in our case the ratio is 10:1 and thus we will be using a maximum of 5 predictors in our regression analysis.

$\mathrm{R}$ is a measure of the correlation between the observed value and the predicted value of the criterion variable. In our study case this would be the correlation between the hiring rating score of our participants and the levels predicted for them by our predictor variables: job performance. R Square (R2) is the square of this measure of correlation and indicates the proportion of the variance in the criterion variable which is accounted for by our model - in our example the proportion of the variance in the job performances scores accounted for by our predictor variable: hiring rating score.

However, R square tends to somewhat over-estimate the success of the model when applied to the real world, so an Adjusted R Square value is calculated which takes into account the number of variables in the model and the number of observations (participants) our model is based on. This Adjusted R Square value gives the most useful measure of the success of our model.

The coefficient of adjusted $\mathrm{R}$ square $=0.916$, demonstrates $91 \%$ of the variability in job performance rating can be accounted for the hiring rating score (Table 5). The calculated statistical significance is $\mathrm{F}=544.140, p<$ 0.001 , which demonstrates that the hiring rating score represents a significant predictor of job performance. The standardized coefficient Beta of 0,958 is also statistically significant at a $p<0.001$, based on the tistribution. The beta value is a measure of how hiring rating score predictor influences the criterion variable, job performance rating, beta being equivalent to the correlation coefficient between the predictor and the criterion variable.

One limit of this study is that the effect might have been overestimated due to multicollinearity in running hierarchical regression analyses.

As seen in Table 6, our first hypothesis is validated, both coefficients 0.958 and $0.313 p<0.001$, show strong correlations between hiring rating scores and job performance evaluation (Rating 2013) and salary.

Hypothesis 2: Hiring rating score (HRS) calculated with Fuzzy Expert System will have an increased impact on predicting long-term job performance (1 to 3 years from hiring year) than classical weighted calculated HRS. 
Table 5. Summary of regression analysis for hiring rating score predicting job performance.

\begin{tabular}{|c|c|c|c|c|c|c|c|c|c|}
\hline \multicolumn{10}{|c|}{ Model Summary } \\
\hline \multirow[b]{2}{*}{ Model } & \multirow[b]{2}{*}{$\mathrm{R}$} & \multirow[b]{2}{*}{ R Square } & \multirow{2}{*}{$\begin{array}{l}\text { Adjusted R } \\
\text { Square }\end{array}$} & \multirow{2}{*}{$\begin{array}{l}\text { Std. Error of } \\
\text { the Estimate }\end{array}$} & \multicolumn{5}{|c|}{ Change Statistics } \\
\hline & & & & & $\begin{array}{l}\text { R Square } \\
\text { Change }\end{array}$ & F Change & df1 & df2 & $\begin{array}{l}\text { Sig. F } \\
\text { Change }\end{array}$ \\
\hline 1 & $0.958^{\mathrm{a}}$ & 0.917 & 0.916 & 0.20008 & 0.917 & 544.140 & 1 & 49 & 0.000 \\
\hline
\end{tabular}

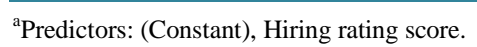

\begin{tabular}{|c|c|c|c|c|c|c|}
\hline \multicolumn{7}{|c|}{ ANOVA $^{b}$} \\
\hline & Model & Sum of Squares & df & Mean Square & $\mathrm{F}$ & Sig. \\
\hline \multirow{3}{*}{1} & Regression & 21.783 & 1 & 21.783 & 544.140 & $0.000^{\mathrm{a}}$ \\
\hline & Residual & 1.962 & 49 & 0.040 & & \\
\hline & Total & 23.745 & 50 & & & \\
\hline
\end{tabular}

${ }^{\mathrm{a} P r e d i c t o r s: ~(C o n s t a n t), ~ H i r i n g ~ r a t i n g ~ s c o r e ; ~}{ }^{\mathrm{b}}$ Dependent Variable: Job performance (Rating 2013).

\begin{tabular}{|c|c|c|c|c|c|c|}
\hline \multicolumn{7}{|c|}{ Coefficients $^{\mathrm{a}}$} \\
\hline & \multirow{2}{*}{ Model } & \multicolumn{2}{|c|}{ Unstandardized Coefficients } & \multirow{2}{*}{$\begin{array}{c}\text { Standardized } \\
\text { Coefficients } \\
\text { Beta }\end{array}$} & \multirow{2}{*}{$\mathrm{t}$} & \multirow{2}{*}{ Sig. } \\
\hline & & $\mathrm{B}$ & Std. Error & & & \\
\hline \multirow{2}{*}{1} & (Constant) & 0.405 & 0.118 & & 3.423 & 0.001 \\
\hline & Hiring rating score & 0.975 & 0.042 & 0.958 & 23.327 & 0.000 \\
\hline
\end{tabular}

${ }^{\mathrm{a} D e p e n d e n t ~ V a r i a b l e: ~ J o b ~ p e r f o r m a n c e ~(R a t i n g ~ 2013) . ~}$

Table 6. Correlation matrix between hiring rating scores, job performance scores and salary $(\mathrm{N}=51)$.

\begin{tabular}{|c|c|c|c|c|c|}
\hline & M & SD & (1) & (2) & (3) \\
\hline Hiring rating (1) & 2.75 & 0.68 & - & & \\
\hline Rating 2013 (2) & 3.09 & 0.69 & $0.958^{* *}$ & - & \\
\hline Salary (3) & 6966.65 & 6348.59 & $0.313^{*}$ & $0.423^{* *}$ & - \\
\hline
\end{tabular}

${ }^{* * *}$ Correlation is significant at the 0.01 level (2-tailed); ${ }^{*}$ Correlation is significant at the 0.05 level (2-tailed).

To test Hypothesis 2, that Fuzzy calculated hiring rating score will be positively related to job performance rating (Rating 2013) and will have a higher relevance on predicting job performance than classical HRS, a regression analysis was conducted. Fuzzy hiring rating score was the independent variable with job performance rating (Rating 2013) dependent variable.

The coefficient of adjusted $\mathrm{R}$ square of 0.965 , demonstrates that $96 \%$ of the variability in job performance can be accounted for the Fuzzy hiring rating score (Table 7). The calculated statistical significance is $\mathrm{F}=1391.4, p$ $<0.001$, which demonstrates that the Fuzzy hiring rating score represents a significant predictor of job performance. The standardized coefficient Beta of 0,983 is also statistically significant at a $p<0.001$ based on the $t$ 
Table 7. Variability in job performance that can be accounted for the Fuzzy hiring rating score.

\begin{tabular}{|c|c|c|c|c|c|c|c|c|c|}
\hline \multicolumn{10}{|c|}{ Model Summary } \\
\hline \multirow[b]{2}{*}{ Model } & \multirow[b]{2}{*}{$\mathrm{R}$} & \multirow[b]{2}{*}{ R Square } & \multirow{2}{*}{$\begin{array}{l}\text { Adjusted R } \\
\text { Square }\end{array}$} & \multirow{2}{*}{$\begin{array}{l}\text { Std. Error of the } \\
\text { Estimate }\end{array}$} & \multicolumn{5}{|c|}{ Change Statistics } \\
\hline & & & & & $\begin{array}{l}\text { R Square } \\
\text { Change }\end{array}$ & F Change & df1 & df2 & Sig. F Change \\
\hline 1 & $0.983^{\mathrm{a}}$ & 0.966 & 0.965 & 0.12839 & 0.966 & 1391.400 & 1 & 49 & 0.000 \\
\hline
\end{tabular}

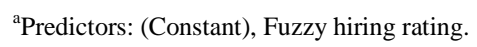

\begin{tabular}{|c|c|c|c|c|c|c|}
\hline \multicolumn{7}{|c|}{ ANOVA $^{\mathrm{b}}$} \\
\hline & Model & Sum of Squares & $\mathrm{df}$ & Mean Square & $\mathrm{F}$ & Sig. \\
\hline \multirow{3}{*}{1} & Regression & 22.937 & 1 & 22.937 & 1391.400 & $0.000^{\mathrm{a}}$ \\
\hline & Residual & 0.808 & 49 & 0.016 & & \\
\hline & Total & 23.745 & 50 & & & \\
\hline
\end{tabular}

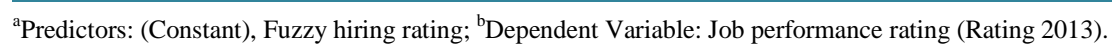

\begin{tabular}{|c|c|c|c|c|c|c|}
\hline \multicolumn{7}{|c|}{ Coefficients $^{\mathrm{a}}$} \\
\hline & \multirow{2}{*}{ Model } & \multicolumn{2}{|c|}{ Unstandardized Coefficients } & \multirow{2}{*}{$\begin{array}{c}\text { Standardized } \\
\text { Coefficients } \\
\text { Beta }\end{array}$} & \multirow{2}{*}{$\mathrm{t}$} & \multirow{2}{*}{ Sig. } \\
\hline & & B & Std. Error & & & \\
\hline \multirow{2}{*}{1} & (Constant) & 0.539 & 0.071 & & 7616 & 0.000 \\
\hline & Fuzzy_hiring rating & 0.902 & 0.024 & 0.983 & 37.301 & 0.000 \\
\hline
\end{tabular}

${ }^{\mathrm{a} D e p e n d e n t ~ V a r i a b l e: ~ J o b ~ p e r f o r m a n c e ~ r a t i n g ~(R a t i n g ~ 2013) . ~}$

distribution. Again, one limit of this study is that the effect might have been overestimated due to multicollinearity in running hierarchical regression analyses.

As described before, during the validation of the first Hypothesis, the coefficient of adjusted $\mathrm{R}$ square of 0.916, demonstrates that $91 \%$ of the variability in job performance rating can be accounted for the classical hiring rating score.

As for the second Hypothesis, we have found that the coefficient of adjusted R square of 0.965 , demonstrating $96 \%$ of the variability in income can be accounted for the Fuzzy hiring rating score, is more relevant than the coefficient of adjusted R square of 0.916 , demonstrating $91 \%$ of the variability in job performance rating can be accounted for the hiring rating score. This increase of $5 \%$ in relevance represents an optimization in the engineering highly standardized context. One limit of this increase can be put on the fact that Fuzzy expert system has used additive single variables in predicting long term job performance, such as: age and background experience of candidates, variables that accounted, in a positive manner for interview rating, so the effect might have been overestimated.

This hypothesis and findings clearly demonstrate that in order to gain a better prediction of future job performance of the candidate we should always choose the Fuzzy logic instead of classical weighted formula. In the context of describing human abilities and their impact on future long term job performance it is more convenient to operate with linguistic terms that offer an interval view, not a static, punctual view such as classic logic.

\section{Discussion}

The present study aimed to extend the use of cognitive ability (numeric and verbal abilities) to predicting long- 
term job performance (from 1 to 3 years) in the automotive multinational companies oriented towards mass production. The results supported the expectation that aptitude test score and interview ratings was positively related to job performance indicators and these results were consistently significant.

The first hypothesis was totally supported. When the hiring rating score was entered as predictors of job performance, a significant model was observed. This model accounted for 91 percent of the variance. The findings from this study are consistent with previous research (Hough \& Oswald, 2000 [9]; Schmidt \& Hunter, 1998, 2004 [7]; Viswesvaran \& Ones, 2002 [26]) that has found a relationship between aptitude and job performance.

Hypothesis 2, presuming that hiring rating score (HRS) calculated with Fuzzy Expert System will have a higher relevance on predicting job performance than classical weighted calculated HRS, was supported. We have found that the coefficient of adjusted $\mathrm{R}$ square of 0.965 , demonstrating $96 \%$ of the variability in income can be accounted for the Fuzzy hiring rating score, is more relevant than the coefficient of adjusted R square of 0.917, demonstrating $91 \%$ of the variability in job performance rating can be accounted for the hiring rating score. This increase of $5 \%$ in relevance represents an optimization in the engineering highly standardized context, although this effect might have been overestimated due to multicollinearity in running hierarchical regression analyses. Another limit of this increase can be put on the fact that Fuzzy expert system has used additive single variables in predicting long term job performance, such as: age and background experience of candidates, variables that accounted, in a positive manner for interview rating, so the effect might have been overestimated.

This hypothesis and findings clearly demonstrate that in order to gain a better prediction of future job performance of the candidate we should always choose the inference rules to shape up the best candidate. Fuzzy logic has opened a door into standardizing scores from a more flexible point of view, dealing with qualitative linguistic terms.

We have suggested that the Company formula for calculating the hiring rating score might be sometimes restrictive in predicting long term job performance (1 to 3 years from the hiring year). The classical formula consists of three weighted aspects: numeric ability score, verbal ability score and interview rating.

As we have emphasized, Fuzzy logic represents a mathematical technique for dealing with imprecise data, works with ranges of values, solving problems in a way that more resembles human logic that must react to an imperfect environment of highly variable, volatile or unpredictable conditions. We have set inference rules, decision rules that establish correspondences between variables such as age, background experience, numeric and verbal abilities and interview ratings, in order to determine the level of professional expertise for a long term job performance.

Thus, the whole picture of future job performance is based on a intercorrelation between factors such as age, background experience, numeric and verbal abilities and interview ratings, where each variable brings substantial value to each possible aspect encountered in recruitment practice. This type of expert system assisted recruitment procedure is designed to focus the attention on the relevant aspects of all input variables, in order to make the optimal recruiting decision for a future job performance of the candidate.

We would expect that in a future research the problem on data multicollinearity and the false negative candidate problem occurring in this Fuzzy expert system will be more detailedly addressed.

Human resources selection process approached by fuzzy, want to avoid toxic decision-making, eliminating the subjective factor which can distort the final outcome, the most appropriate candidates (Balas Timar \& Balas; 2007) [26].

\section{References}

[1] Goleman, D. (1998) Working with Emotional Intelligence. Bloomsbury Publishing, London.

[2] Sonnentag, S. and Lange, I. (2002) The Relationship between High Performance and Knowledge about How to Master Cooperation Situations. Applied Cognitive Psychology, 16, 491-508. http://dx.doi.org/10.1002/acp.805

[3] Nash, J., Collins, B., Loughlin, S., Solbrig, M., Harvey, R. and Krishnan-Sarin, S. (2003) Training the Transdisciplinary Scientist: A General Framework Applied to Tobacco Use Behavior. Nicotine and Tobacco Research, 5, S41-S53. http://dx.doi.org/10.1080/14622200310001625528

[4] Fiore, S. M., Bedwell, W. and Salas, E. (2011) Interpersonal Skills Assessment: Social and Collaborative Factors and the 21st Century Workforce. Presented at the National Academies of Science Workshop on "Assessment of 21st Century Skills”, University of California-Irvine, January, 2011.

[5] Schmidt, F.L. (2002) The Role of General Cognitive Ability and Job Performance: Why There Cannot Be a Debate. 
Human Performance, 15, 187-210. http://dx.doi.org/10.1080/08959285.2002.9668091

[6] Schmidt, F.L., Hunter, J.E., McKenzie, R. and Muldrow, T. (1979) The Impact of Valid Selection Procedures on Workforce Productivity. Journal of Applied Psychology, 64, 609-626. http://dx.doi.org/10.1037/0021-9010.64.6.609

[7] Gatewood, R. and Field, H. (2001) Human Resource Selection. Harcourt Brace \& Company, Orlando.

[8] Schmidt, F.L., Hunter, J.E., Pearlman, K. and Hirsh, H.R. (1985) Forty Questions about Validity Generalization and Meta-Analysis. Personnel Psychology, 38, 697-798. http://dx.doi.org/10.1111/j.1744-6570.1985.tb00565.x

[9] Schmidt, F.L. and Hunter, J.E. (1998) The Validity and Utility of Selection Methods in Personnel Psychology: Practical and Theoretical Implications of 85 Years of Research Findings. Psychological Bulletin, 124, 262-274. http://dx.doi.org/10.1037/0033-2909.124.2.262

[10] Hunter, J.E. (1986) Cognitive Ability, Cognitive Aptitudes, Job Knowledge, and Job Performance. Journal of Vocational Behavior, 29, 340-362. http://dx.doi.org/10.1016/0001-8791(86)90013-8

[11] Hunter, J.E. and Schmidt, F.L. (1996) Intelligence and Job Performance: Economic and Social Implications. Psychology, Public Policy and Law, 2, 447-472. http://dx.doi.org/10.1037/1076-8971.2.3-4.447

[12] Schmidt, F.L., Hunter, J.E., Outerbridge, A.N. and Trattner, M.H. (1986) The Economic Impact of Job Selection Methods on the Size, Productivity and Payroll Costs of the Federal Work-Force: An Empirical Demonstration. Personnel Psychology, 39, 1-29. http://dx.doi.org/10.1111/j.1744-6570.1986.tb00572.x

[13] Schmidt, F.L. (1995) Why All Banding Procedures in Personnel Selection Are Logically Flawed. Human Performance, 8, 165-177. http://dx.doi.org/10.1207/s15327043hup0803_33

[14] Outtz, J.L. (2002) The Role of Cognitive Ability Tests in Employment Selection. Human Performance, 15, $161-171$. http://dx.doi.org/10.1080/08959285.2002.9668089

[15] Hough, L.M. and Oswald, F.L. (2000) Personnel Selection: Looking toward the Future-Remembering the Past. Annual Review of Psychology, 51, 631-664. http://dx.doi.org/10.1146/annurev.psych.51.1.631

[16] Klein, C., DeRouin, R.E. and Salas, E. (2006) Uncovering Workplace Interpersonal Skills: A Review, Framework and Research Agenda. International Journal of Industrial and Organizational Psychology, 21, 79-126.

[17] Riggio, R.E. and Zimmerman, J. (1991) Social Skills and Interpersonal Relationships: Influences on Social Support and Support Seeking. Advances in Personal Relationships, 2, 133-155.

[18] Schneider, R.J., Ackerman, P.L. and Kanfer, R. (1996) To Act Wisely in Human Relations: Exploring the Dimensions of Social Competence. Personality and Individual Differences, 21, 469-481. http://dx.doi.org/10.1016/0191-8869(96)00084-0

[19] Sherer, M., Maddux, J.E., Mercandante, B., Prentice-Dunn, S., Jacobs, B. and Rogers, R.W. (1982) The Self-Efficacy Scale: Construction and Validation. Psychological Reports, 51, 663-671. http://dx.doi.org/10.1016/0191-8869(96)00084-0

[20] Viswesvaran, C. and Ones, D.S. (2002) Agreements and Disagreements on the Role of General Mental Ability (GMA) in Industrial, Work and Organizational Psychology. Human Performance, 15, 211-231. http://dx.doi.org/10.1080/08959285.2002.9668092

[21] Brannick, M.T. and Levine, E.L. (2002) Job Analysis: Methods Research and Applications. Sage Publications, Thousand Oaks.

[22] Tenopyr, M.L. (2002) Theory versus Reality: Evaluation of g in the Workplace. Human Performance, 15, $107-122$. http://dx.doi.org/10.1080/08959285.2002.9668086

[23] Alexander, S.G. (2007) Predicting Long Term Job Performance Using a Cognitive Ability Test. Ph.D. Disertation (Industrial Organizational Psychology), University of North Texas, Denton.

[24] Schmidt, F.L. and Hunter, J.E. (2004) General Mental Ability in the World of Work: Occupational Attainment and Job Performance. Journal of Personality and Social Psychology, 86, 162-173. http://dx.doi.org/10.1037/0022-3514.86.1.162

[25] Zadeh, L.A. (1965) Fuzzy Sets. Information and Control, 8, 338-353. http://dx.doi.org/10.1016/S0019-9958(65)90241-X

[26] Balas-Timar, D. and Balas, V. E. (2007) Decision Making in Human Resources Selection Methodology. 2nd IEEE International Workshop on Soft Computing Applications, SOFA 2007, 21-23 August 2007, Gyula-Hungary, Oradea-Romania, 123-127, IEEE Catalog Number: CFP0728D. http://dx.doi.org/10.1109/SOFA.2007.4318316 
Scientific Research Publishing (SCIRP) is one of the largest Open Access journal publishers. It is currently publishing more than 200 open access, online, peer-reviewed journals covering a wide range of academic disciplines. SCIRP serves the worldwide academic communities and contributes to the progress and application of science with its publication.

Other selected journals from SCIRP are listed as below. Submit your manuscript to us via either submit@scirp.org or Online Submission Portal.
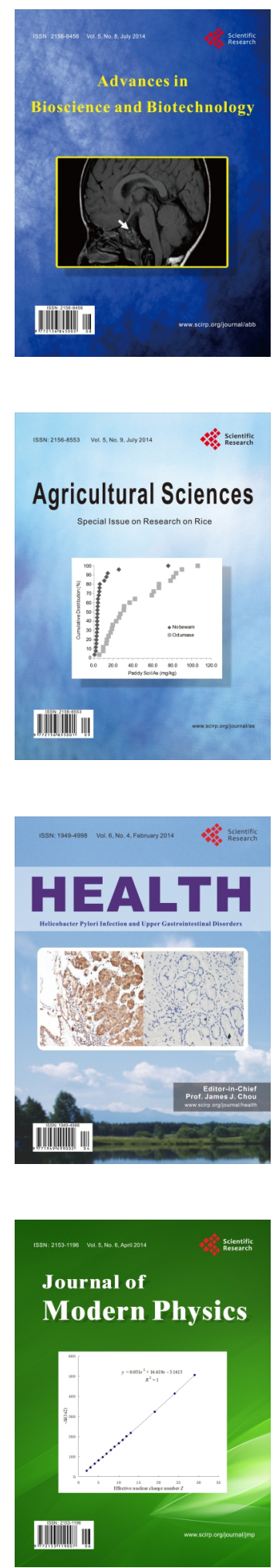
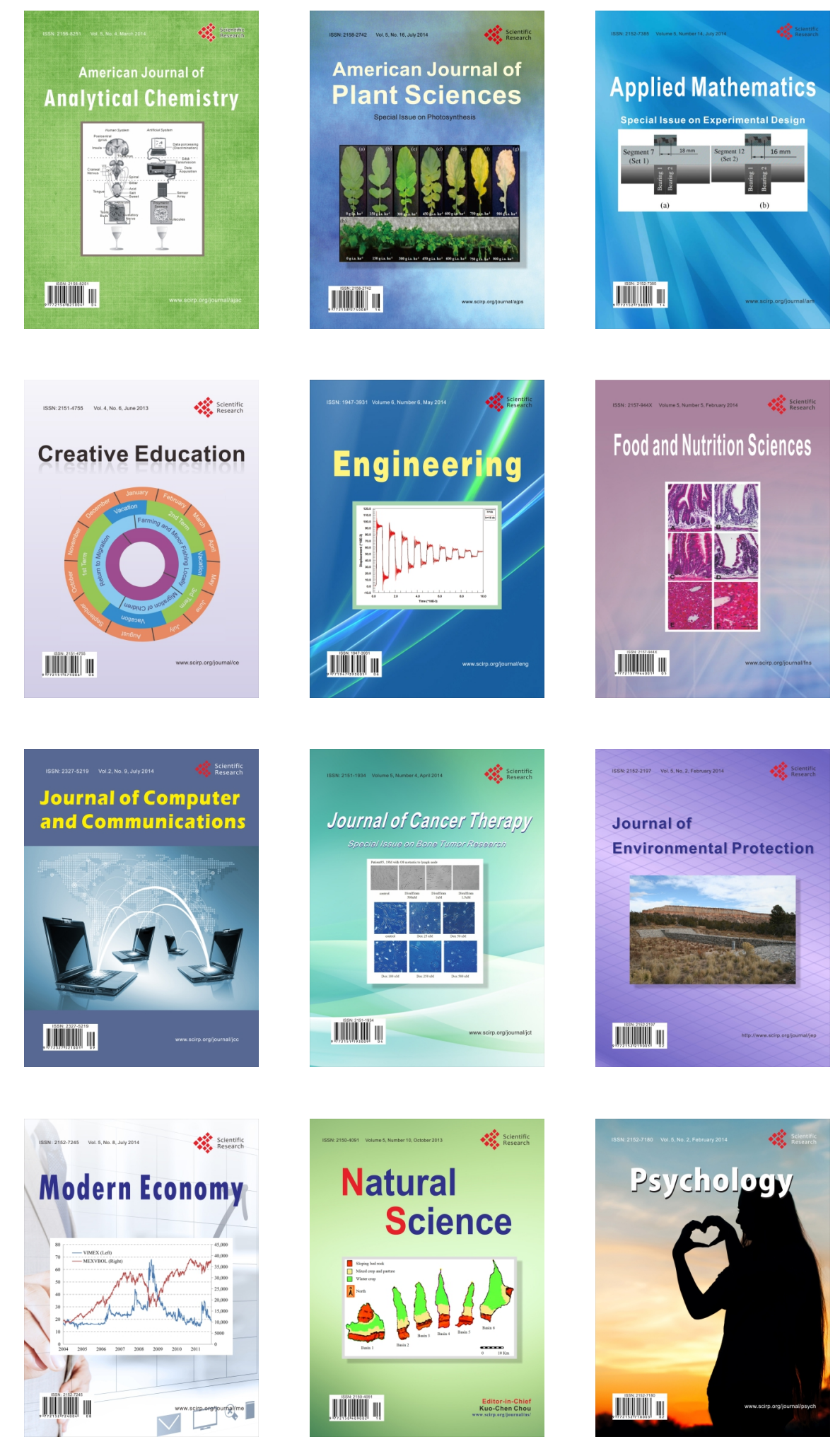